\title{
Sexual Sadism
}

National Cancer Institute

\section{Source}

National Cancer Institute. Sexual Sadism. NCI Thesaurus. Code C94358.

A disorder characterized by recurrent sexual urges, fantasies, or behaviors involving acts (real, not simulated) in which the psychological or physical suffering of a victim is sexually exciting to the individual. 